\title{
Association of inflammatory bowel disease risk loci with sarcoidosis, and its acute and chronic subphenotypes
}

\author{
A. Fischer*, M. Nothnagel\#, A. Franke*, G. Jacobs*, H.R. Saadati*, K.I. Gaede \\ P. Rosenstiel*,+, M. Schürmann ${ }^{\S}$, J. Müller-Quernheim ${ }^{f}$, \\ S. Schreiber*,+ and S. Hofmann*
}

ABSTRACT: Sarcoidosis is a complex granulomatous inflammatory disorder that shares several clinical and pathogenic features with inflammatory bowel disease (IBD). Postulating a common genetic basis of inflammatory diseases, we tested 106 single-nucleotide polymorphisms (SNPs) that are known or have been suggested to be associated with IBD for a potential association with sarcoidosis and its acute and chronic subphenotypes.

We genotyped 1,996 German sarcoidosis patients, comprising 648 acutely and 1,161 chronically affected individuals, 2,622 control subjects, and 342 German trios with affected offspring using SNPlex ${ }^{\mathrm{TM}}$ technology.

The nonsynonymous SNP rs11209026 (Arg381GIn) in the interleukin (IL)-23 receptor (IL23R) gene was associated with chronic sarcoidosis (OR $0.63 ; p=5.58 \times 10^{-5}$ ), which was supported by the result of a transmission disequilibrium test analysis in the independent family sample (OR $0.50 ; p=0.031$ ). Marker rs12035082 located at chromosome $1 q 24.3$ was found to be associated with the acute subphenotype (OR 1.36; $p=6.80 \times 10^{-7}$ ) and rs916977 (HERC2 locus; OR 1.30; $p=4.49 \times 10^{-5}$ ) was associated with sarcoidosis.

Our results highlight the potential importance of the IL-23 signalling pathway for the development of chronic sarcoidosis. The finding links sarcoidosis pathogenesis to other inflammatory conditions and may contribute to new hypotheses on disease mechanisms.

KEYWORDS: HERC2, IL23R, inflammation, rs11209026, rs12035082

everal immune-related susceptibility genes have been demonstrated as shared risk factors for chronic inflammatory disorders. These include PTPN22 and CTLA4 (various autoimmune diseases [1, 2]), NOD2 (Crohn's disease (CD) [3, 4] and atopic diseases $[5,6])$ and IL23R (CD $[7,8]$, psoriasis [9] and ankylosing spondylitis [10-12]). In particular, CD and ulcerative colitis (UC), the two main phenotypes of inflammatory bowel disease (IBD), share a number of susceptibility loci (e.g. NKX2-3, CCNY, STAT3 and PTPN2) [13, 14]. Presumably, this overlap of genetic risk loci, as well as familial clustering of different autoimmune diseases [15], indicates that shared biological pathways may be involved in the aetiology of clinically distinct immune-mediated diseases (reviewed in [16-18]).
Sarcoidosis (Online Mendelian Inheritance in Man (OMIM) \#181000) is an inflammatory disorder that can be further classified into acute or chronic sarcoidosis according to the course of the disease. It shares several clinical and immunological features with other chronic inflammatory diseases, such as general inflammatory characteristics, or more specifically, the formation of noncaseating granuloma in CD. Furthermore, sarcoidosis is a complex polygenic disorder, to which variants in numerous genes and yet unknown environmental factors are likely to contribute [19]. The genetic underpinning in sarcoidosis is supported by the discovery of two susceptibility genes, namely BTNL2 [20,21] and ANXA11 [22]. Besides these disease loci, numerous case-control association studies of potential candidate regions have been published for

\section{AFFILIATIONS}

*Institute of Clinical Molecular Biology,

\#Institute of Medical Informatics and Statistics, Christian-Albrechts University,

${ }^{+}$Dept of General Internal Medicine, University Hospital SchleswigHolstein, Campus Kiel, Kiel, - Research Center Borstel, Dept of Pneumology, Borstel,

${ }^{\S}$ Institute of Human Genetics, University of Lübeck, Lübeck, and ${ }^{f}$ Dept of Pneumology, University of Freiburg, Freiburg, Germany.

CORRESPONDENCE

S. Hofmann

Institute of Clinical Molecular Biology Christian-Albrechts University

Schittenhelmstraße 12

Kiel

Germany

E-mail: s.hofmann@ikmb.uni-kiel.de

Received:

March 282010

Accepted after revision: June 282010

First published online:

July 222010 
sarcoidosis, but many of them with conflicting results (for review, see [23]). This includes the chemokine receptor genes CCR2 and CCR5 on chromosome 3p21.3, IL18, TNFA and several HLA loci. Most of these genes seem to play key roles in the pathogenesis of other immune disorders, such as IL18 or TNFA in CD (for review, see [24]). Furthermore, we recently identified a novel shared susceptibility locus on chromosome (chr)10p12.2 for both sarcoidosis and CD by combining genome-wide association datasets from the two diseases [25]. This underlines the aforementioned hypothesis that a number of genetic regions exist that may act as general modifiers of the inflammatory response.

Here, we aimed to identify the putative effects of genetic variants in 74 IBD risk loci on the susceptibility to sarcoidosis, and to its acute and chronic subphenotypes. With this approach, we were able to identify HERC2 as a novel susceptibility gene for sarcoidosis, and chr12q24.3 and IL23R as subphenotype-specific risk loci for the acute and chronic subphenotype.

\section{MATERIALS AND METHODS Patients and control subjects}

A total of 1,996 unrelated German sarcoidosis patients and 2,622 unrelated German controls were included in the study. All patients were recruited through specialised hospitals and practitioners, the German sarcoidosis patients' organisation (Deutsche Sarkoidose-Vereinigung e.V.; www.sarkoidose.de), and via health insurance institutions. In the latter case, histological confirmation of the diagnosis was necessary for inclusion of individuals. All patients completed a questionnaire on the course of disease. Patients' physicians were contacted to provide clinical radiology and laboratory data required to confirm the diagnosis of sarcoidosis. According to the clinical presentation of the disease, patients were classified as having either chronic or acute sarcoidosis, if possible. The acute sarcoidosis group comprised patients with sudden complaints and recovery within 2 yrs, including patients with Löfgren's syndrome. Individuals with the chronic phenotype of sarcoidosis exhibited subtly intensifying early symptoms, followed by enduring disease activity for $\geqslant 2$ yrs. In order to reduce phenotypic heterogeneity, sarcoidosis patients were separated into 648 individuals with acute sarcoidosis, including 105 patients with Löfgren's syndrome, and 1,161 persons with the chronic form of the disease, 734 of whom suffered from enduring disease despite cortisone therapy and 427 of whom experienced recovery with or without treatment. As the remaining 187 patients could not be classified unequivocally as to the course of the disease, these individuals were excluded from the subphenotype-specific analysis. German control individuals were recruited from the PopGen biobank [26]. Written informed consent was obtained from all participants. All collection protocols were approved by institutional ethics review boards and data protection authorities of the participating institutes.

The family sample comprised 342 German trios with offspring affected by sarcoidosis. Of these, 121 trios comprised offspring with the acute form of the disease and offspring of 255 trios were affected by chronic sarcoidosis. Recruitment and diagnosis was accomplished as described above for the casecontrol sample.

\section{Single-nucleotide polymorphism selection, genotyping and quality control}

All 106 single-nucleotide polymorphisms (SNPs) included in this study were selected from prior publications for their confirmed or suggested association with CD and/or UC. The majority of these markers (58 SNPs) were originally published by the Wellcome Trust Case-Control Consortium [27] or were identified through the meta-analysis performed by BARRETT et al. [14] (see Table S1 in the online supplementary material for details). Ligation-based SNPlex ${ }^{\mathrm{TM}}$ genotyping [28] was performed as previously described [29]. Genotype assignments were manually confirmed by visual inspection with the Genemapper 4.0 (Applied Biosystems, Carlsbad, CA, USA) software. All process data were written to and administered by an in-house database-driven laboratory information management system described previously [30]. All samples and SNPs included in the analysis met the following quality criteria: all samples had a call rate $\geqslant 0.9$; and markers had a minor allele frequency $\geqslant 0.02$, a call rate $\geqslant 0.95$ and showed no deviation from Hardy-Weinberg equilibrium in the control sample ( $p>0.01$ in the exact test implemented in PLINK v1.06 [31]). For further quality assessment, at total of 129,840 genotypes from 55 randomly chosen SNPs was technically replicated showing a concordance rate of $99.8 \%$ between the two batches.

\section{Statistical analysis}

Statistical data analysis was carried out using PLINK v1.06 [32]. Allele frequency differences were assessed using a Chisquared test (one degree of freedom (df)). Nominal p-values were adjusted for multiple testing using Bonferroni correction with a factor of 318, accounting for all 106 markers under study and the three investigated phenotypes. Power calculation for the transmission disequilibrium test (TDT) analysis was conducted using the Genetic Power Calculator [33] and for case-control analysis using the PS power and sample size program [34].

\section{Analysis of specific expression of IL23R by RT-PCR}

For investigation of tissue- and cell type-specific expression patterns of IL23R, we used standard RT-PCR procedures on a commercially available human tissue and immune panel from Clontech (Palo Alto, CA, USA). Bronchoalveolar lavage (BAL) cell samples were taken from five patients with sarcoidosis and without steroid treatment at the time of BAL and five unaffected individuals. The diagnosis of sarcoidosis was established retrospectively in accordance with previously defined criteria [35], including noncaseating granuloma identified by transbronchial biopsies. All patients and unaffected individuals gave their informed consent to participate in the study. BAL was performed as previously described [36]. The BAL cell suspensions used in this study contained $>95 \%$ alveolar macrophages. Briefly, the PCR program used was applied as follows: denaturation for $5 \mathrm{~min}$ at $95^{\circ} \mathrm{C} ; 33$ cycles of $20 \mathrm{~s}$ at $95^{\circ} \mathrm{C}, 20 \mathrm{~s}$ at $53^{\circ} \mathrm{C}$ and $60 \mathrm{~s}$ at $72^{\circ} \mathrm{C}$; and a final extension for $5 \mathrm{~min}$ at $72^{\circ} \mathrm{C}$. The following primers were used for amplification: hIL23R-F1 (GACACATGGAATTCTGGGCT) and hIL23R-R1 (CAAAAGCATGGTGGTTTCCT). To confirm the use of equal amounts of RNA in each experiment, all samples were checked in parallel for glyceraldehyde 3-phosphate dehydrogenase $(G A P D H)$ expression using the following primers: GAPDH-F (CCAGCCGAGCCACATCGC) and GAPDH-R 
(ATGAGCCCCAGCCTTCTCCAT). All amplified DNA fragments were analysed on $1 \%$ agarose gels, and subsequently documented and quantified using a ChemiDoc XRS system (BioRad, Munich, Germany).

\section{RESULTS}

\section{Case-control association analysis}

A total of 106 SNPs from 74 different loci passed the quality control criteria (see Methods section). In the association analysis, 24 SNPs from 21 different loci reached nominal significance with nominal p-value (pnom) of $<0.05$ in the allelic Chi-squared test (one df) in the overall sample of 1,996 sarcoidosis cases and 2,622 controls. In the subphenotypespecific analysis, eight of these SNPs were also nominally associated (pnom $<0.05)$ with acute sarcoidosis $(648$ cases) and 16 with the chronic form of the disease (1,161 cases). Three distinct SNPs were nominally significant solely for acute sarcoidosis and further four SNPs for chronic sarcoidosis only. Detailed results for all SNPs under study, including genotype counts, are shown in online supplementary Table S2.

Since every SNP was tested in the overall, acute and chronic samples, nominal p-values were Bonferroni-corrected for $3 \times 106=318$ independent tests. Three association signals, namely from rs916977, rs11209026 and rs12035082, remained significant after correction for multiple testing (table 1). SNP rs916977, which is located in intron 12 of the HECT domain and RLD 2 (HERC2) gene on chr15q13.1, yielded a corrected p-value (pcorr) of 0.014 in the overall sarcoidosis sample (OR $1.30,95 \%$ CI 1.15-1.48), with both subphenotypes contributing to the signal to a similar extent (ORacute 1.34, 95\% CI 1.12-1.61; ORchronic $1.29,95 \%$ CI 1.11-1.50). These odd ratios were in the same range as for CD (OR 1.26, 95\% CI 1.07-1.47), but reduced compared to UC (OR 1.46, 95\% CI 1.23-1.75), as reported previously for a German sample [37]. Furthermore, two subphenotype-specific associations were observed: the nonsynonymous SNP rs11209026 in the interleukin (IL)-23 receptor (IL23R) gene, which is a well established risk factor for CD $[7,14,37,38]$, was solely associated with chronic sarcoidosis
(ORchronic 0.63, 95\% CI 0.50-0.79; pcorr,chronic $=0.018$ ). The effect of this SNP only slightly differed between patients with enduring disease despite cortisone treatment and patients that experienced recovery (OR 0.66 (95\% CI $0.50-0.68)$ and OR 0.57 (95\% CI 0.40-0.82), respectively). As the IL-23 receptor (IL-23R) directly interacts with Janus kinase 2 (JAK2) at the molecular level [39], it is interesting to note that the two SNPs, rs10758669 and rs10974944, located in the JAK2 gene, are associated with chronic sarcoidosis with nominal significance (ORchronic 1.14 $(95 \%$ CI 1.03-1.26; pchronic $=0.013)$ and ORchronic $1.16(95 \%$ CI 1.04-1.30; pchronic $=0.0061$ ), respectively). However, no epistatic effects were detected between IL23R and JAK2 SNPs (data not shown). Finally, an exclusive association with acute sarcoidosis was observed for SNP rs12035082 (ORacute 1.36, $95 \%$ CI 1.21-1.54; pcorr,acute $=2.34 \times 10^{-4}$ ), which is located downstream of the tumour necrosis factor (ligand) superfamily member 18 gene (TNFSF18 or GITRL) on chr1q24.3 and was reported to modestly increase the risk for CD (OR 1.20, 95\% CI 1.05-1.37) [37]. In the Löfgren's disease subsample, this SNP was not significantly associated, probably due to the small number of patients $(n=105$; power $=0.34)$.

\section{Additional evaluation in a family-based design}

In order to substantiate these novel associations, we tested the three markers in an independent family sample comprising 342 German trios with affected offspring, including 121 "acute" trios and 255 "chronic" trios, using the TDT (table 2). SNP rs916977 located in the HERC2 gene, which was found to be associated with sarcoidosis in the population-based design (OR 1.30), yielded a borderline, but not significant, result (OR 0.73, $95 \%$ CI $0.52-1.03 ; \mathrm{p}=0.069 ; 29 \%$ power). Marker rs11209026, located in the IL23R gene, showed a nominal significant association with the chronic subphenotype (OR 0.50, 95\% CI $0.26-0.95$; pchronic $=0.031$ ) and a similar effect size as in the casecontrol analysis (OR 0.63). Finally, SNP rs12035082 was found to have yielded a slightly higher odds ratio (OR 1.50, 95\% CI $0.96-$ $2.35)$ in the acute trios than in the population-based design (OR 1.36), but also only a borderline, nonsignificant $p$-value (pacute $=0.074 ; 27 \%$ power).

\begin{tabular}{|c|c|c|c|c|c|c|c|c|c|c|c|c|c|c|c|}
\hline TABLE 1 & $\begin{array}{l}\text { Resi } \\
\text { or } \mathrm{C}\end{array}$ & $\begin{array}{l}\text { ults } \\
\text { hron }\end{array}$ & $\begin{array}{l}\text { for the thre } \\
\text { ic sarcoid }\end{array}$ & $\begin{array}{l}\text { ees } \\
\text { dosis }\end{array}$ & $\begin{array}{l}\text { ingle } \\
s \text { aft }\end{array}$ & $\begin{array}{l}\text { e-nucleotid } \\
\text { er Bonferro }\end{array}$ & $\begin{array}{l}\text { poly } \\
\text { hi co }\end{array}$ & $\begin{array}{l}\text { norphisms } \\
\text { ection for }\end{array}$ & $\begin{array}{l}\text { SNPs) tha } \\
\text { hultiple tes }\end{array}$ & ema & ed signifi & ntly asso & iatec & with overa & II, acute \\
\hline \multirow[t]{3}{*}{ dbSNP } & \multirow[t]{3}{*}{ Locus } & \multirow[t]{3}{*}{ Chr } & \multirow[t]{3}{*}{ Position } & \multirow[t]{3}{*}{ A1 } & \multirow[t]{3}{*}{ A2 } & \multirow{3}{*}{$\begin{array}{c}\begin{array}{c}\text { Unaffected } \\
\text { controls }\end{array} \\
\text { MAF }\end{array}$} & \multicolumn{9}{|c|}{ Sarcoidosis } \\
\hline & & & & & & & \multicolumn{3}{|c|}{ Overall } & \multicolumn{3}{|c|}{ Acute } & \multicolumn{3}{|c|}{ Chronic } \\
\hline & & & & & & & MAF & $\begin{array}{c}\text { OR } \\
(95 \% \mathrm{Cl})\end{array}$ & $p$-value & MAF & $\begin{array}{c}\text { OR } \\
(95 \% \mathrm{Cl})\end{array}$ & $p$-value & MAF & $\begin{array}{c}\text { OR } \\
(95 \% \mathrm{Cl})\end{array}$ & $p$-value \\
\hline rs11209026 & IL23R & 1 & 67478546 & A & G & 0.07 & 0.05 & $\begin{array}{c}0.71 \\
(0.59-0.85)\end{array}$ & $6.71 \times 10^{-2}$ & 0.06 & $\begin{array}{c}0.84 \\
(0.64-1.09)\end{array}$ & $>1$ & 0.04 & $\begin{array}{c}0.63 \\
(0.50-0.79)\end{array}$ & $1.79 \times 10^{-2}$ \\
\hline rs12035082 & $1 \mathrm{q} 24.3$ & 1 & 171165000 & C & $T$ & 0.39 & 0.42 & $\begin{array}{c}1.15 \\
(1.06-1.25)\end{array}$ & $3.73 \times 10^{-1}$ & 0.46 & $\begin{array}{c}1.36 \\
(1.21-1.54)\end{array}$ & $2.34 \times 10^{-4}$ & 0.40 & $\begin{array}{c}1.07 \\
(0.97-1.18)\end{array}$ & 1 \\
\hline rs916977 & HERC2 & 15 & 26186959 & A & G & 0.11 & 0.13 & $\begin{array}{c}1.30 \\
(1.15-1.48)\end{array}$ & $1.44 \times 10^{-2}$ & 0.14 & $\begin{array}{c}1.35 \\
(1.13-1.62)\end{array}$ & $3.49 \times 10^{-1}$ & 0.13 & $\begin{array}{c}1.29 \\
(1.11-1.50)\end{array}$ & 1 \\
\hline
\end{tabular}

dbSNP: SNPs from the database at http://www.ncbi.nlm.nih.gov/projects/SNP/ Chr: chromosome; A: allele; MAF: minor allele frequency; UNAFF: unaffected controls. $\mathrm{p}$-values are Bonferroni-corrected. Bold represents statistically significant results. 


\begin{tabular}{|c|c|c|c|c|c|c|c|c|c|c|c|c|c|c|c|c|c|}
\hline TABLE 2 & $\begin{array}{l}\text { Resul } \\
\text { signif }\end{array}$ & $\begin{array}{l}\text { Its o } \\
\text { fican }\end{array}$ & $\begin{array}{l}\text { the transr } \\
\text { tly associa }\end{array}$ & niss & $\begin{array}{l}\text { sion } \\
\text { in }\end{array}$ & $\begin{array}{l}\text { dise } \\
\text { the } c\end{array}$ & $\begin{array}{l}\text { quili } \\
\text { ase- }\end{array}$ & $\begin{array}{l}\text { orium test a } \\
\text {-control ass }\end{array}$ & $\begin{array}{l}\text { lalysis for } \\
\text { ciation a }\end{array}$ & $\begin{array}{l}\text { ne tl } \\
\text { alys }\end{array}$ & $\begin{array}{l}\text { hree } \\
\text { is }\end{array}$ & single-nuc & otide poly & nork & his & $s(S N P s) t$ & lat were \\
\hline \multirow[t]{3}{*}{ dbSNP } & \multirow[t]{3}{*}{ Locus } & \multirow[t]{3}{*}{ Chr } & \multirow[t]{3}{*}{ Position } & \multirow[t]{3}{*}{ A1 } & \multirow[t]{3}{*}{ A2 } & \multicolumn{12}{|c|}{ Sarcoidosis } \\
\hline & & & & & & \multicolumn{4}{|c|}{ Overall } & \multicolumn{4}{|c|}{ Acute } & \multicolumn{4}{|c|}{ Chronic } \\
\hline & & & & & & $\mathbf{T}$ & $U$ & $\begin{array}{c}\text { OR } \\
(95 \% \mathrm{Cl})\end{array}$ & p-value & $\mathbf{T}$ & $\mathbf{U}$ & $\begin{array}{c}\text { OR } \\
(95 \% \mathrm{Cl})\end{array}$ & $p$-value & $T$ & $u$ & $\begin{array}{c}\text { OR } \\
(95 \% \mathrm{Cl})\end{array}$ & $p$-value \\
\hline rs11209026 & IL23R & 1 & 67478546 & $A$ & G & 28 & 44 & $\begin{array}{c}0.64 \\
(0.40-1.02)\end{array}$ & $5.94 \times 10^{-2}$ & 10 & 11 & $\begin{array}{c}0.91 \\
(0.39-2.14)\end{array}$ & $8.27 \times 10^{-1}$ & 14 & 28 & $\begin{array}{c}0.50 \\
(0.26-0.95)\end{array}$ & $3.08 \times 10^{-2}$ \\
\hline rs12035082 & $1 \mathrm{q} 24.3$ & 1 & 171165000 & C & $T$ & 155 & 141 & $\begin{array}{c}1.10 \\
(90.88-1.38)\end{array}$ & $4.16 \times 10^{-1}$ & 48 & 32 & $\begin{array}{c}1.50 \\
(0.96-2.35)\end{array}$ & $7.36 \times 10^{-2}$ & 83 & 88 & $\begin{array}{c}0.94 \\
(0.70-1.27)\end{array}$ & $7.02 \times 10^{-1}$ \\
\hline rs916977 & HERC2 & 15 & 26186959 & $T$ & C & 56 & 77 & $\begin{array}{c}0.73 \\
(0.52-1.03)\end{array}$ & $6.86 \times 10^{-2}$ & 18 & 18 & $\begin{array}{c}1.00 \\
(0.52-1.92)\end{array}$ & $>1$ & 33 & 50 & $\begin{array}{c}0.66 \\
(0.43-1.02)\end{array}$ & $6.20 \times 10^{-2}$ \\
\hline
\end{tabular}

dbSNP: SNPs from the database at http://www.ncbi.nlm.nih.gov/projects/SNP/ Chr: chromosome; A: allele; T: transmitted; U: untransmitted. p-values are Bonferronicorrected. Bold represents statistically significant results.

\section{Expression analysis of IL23R}

To gain first insights on a possible effect of IL23R variants on sarcoidosis, the transcript levels of IL23R were assessed by RTPCR in a panel of different healthy human tissues and resting and activated immune cells (fig. 1). The expression analysis in this panel showed elevated IL23R expression in testis and activated CD4+ T-cells and moderate expression in healthy lung tissue. Next, we analysed the expression levels of IL23R in cells derived from BAL cells using quantitative real-time PCR, and cDNA from sarcoidosis patients and unaffected controls ( $n=5$ per group). Statistical analysis revealed no significant differences in relative expression levels between patients and controls (data not shown).

\section{DISCUSSION}

Under the hypothesis of a common genetic basis of inflammatory diseases, we selected SNPs that are known to be

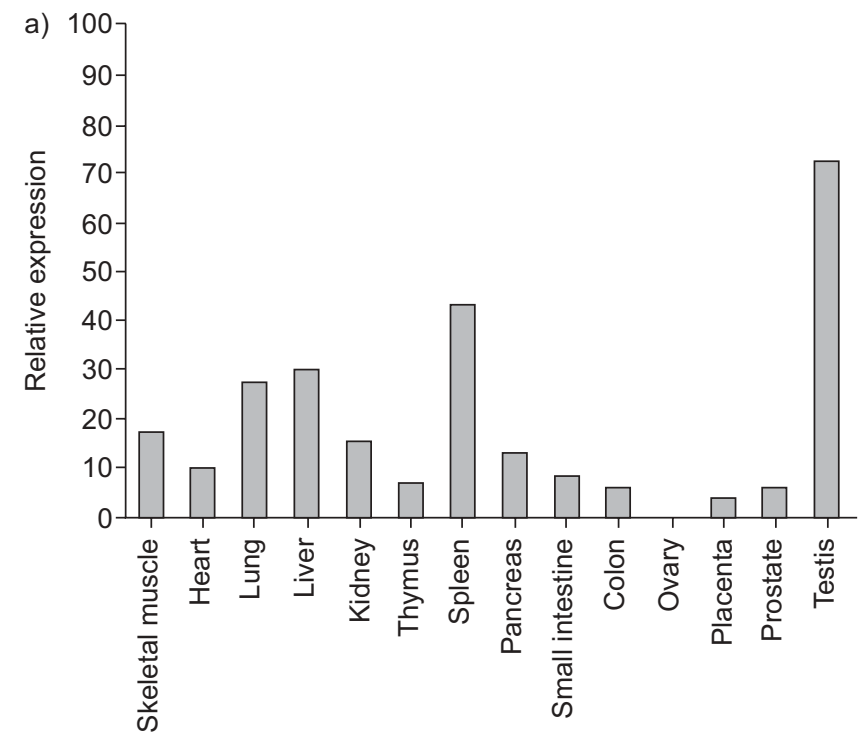

Tissue associated with CD or UC as likely candidates for also playing a role in sarcoidosis aetiology. We identified three significant associations with sarcoidosis, with two being specific to the acute and chronic subphenotypes.

The overall sarcoidosis phenotype was associated with marker rs916977, which is a nonsynonymous SNP in the HERC2 gene. Our study sample originated from Germany and, therefore, we do not expect a significant population structure for this sample [40]. However, allele frequencies of markers located at the HERC2 locus have recently been shown to exhibit a north-south gradient across Europe [41], possibly even within Germany. HERC2 was previously reported to be associated with CD and UC in German and Dutch-Belgian samples [37, 38]. However, neither the association with $\mathrm{CD}$ and UC nor with sarcoidosis was investigated in a well-powered, family-based study and, to

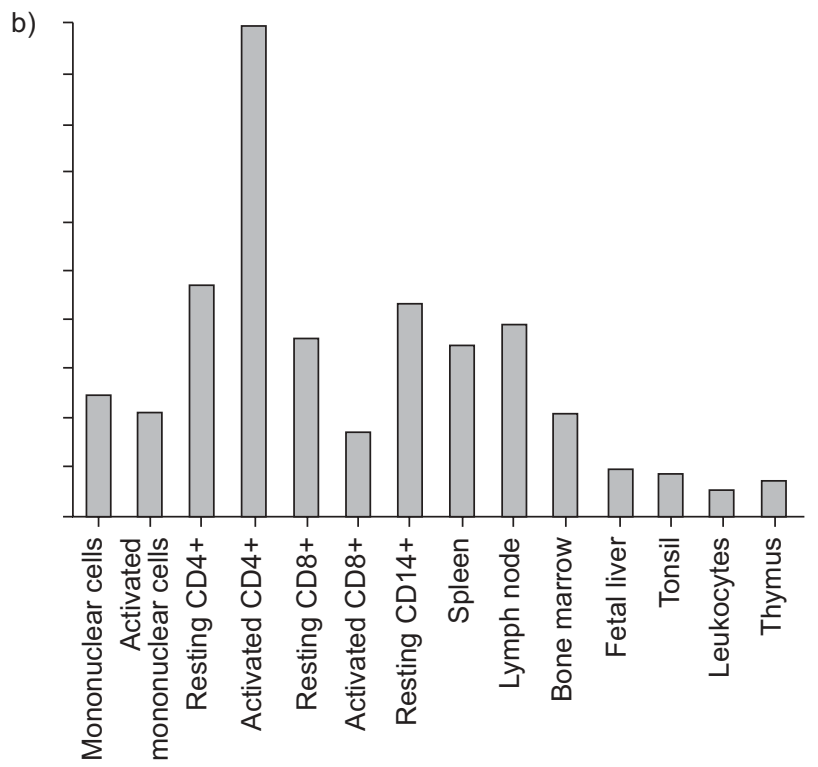

Cell type

FIGURE 1. Relative expression of IL23R mRNA in a) healthy tissue and b) the immune cell panel. 
date, there are no reports of a possible functional role of HERC2 in the inflammatory process. Therefore, the association signal for HERC2 has to be considered with caution and requires further investigation.

The association of IL23R variants with IBD and with a number of chronic inflammatory diseases is well established [7, 9-13, 42-46]. Our study is the first report on an association of an IL23R variant with chronic sarcoidosis (rs11209026; OR 0.63, 95\% CI 0.50-0.79) and provides further support for this signal by the nominal significant association in an independent family sample (OR 0.50, 95\% CI 0.26-0.95). The associated SNP rs11209026 (Arg381Gln) causes an amino acid exchange in the intracellular domain of IL-23R and may thus affect downstream signalling of the receptor. Preliminary expression studies showed elevated IL23R expression in activated CD4+ T-cells and low expression in monocytes, which is consistent with previous findings [39]. In addition, we found moderate expression in healthy lung tissue. Differential IL23R expression has been reported for CD4+ T-cells from UC and CD patients [47]. However, the lack of differential expression of IL23R in BAL cells from sarcoidosis patients compared to healthy individuals (data not shown) does not contradict our genetic finding, mainly because the causative SNP(s) may influence IL23R function rather than mRNA expression.

Signal transduction through IL-23R and the downstream elements of the IL-23 pathway is well characterised. IL-23 signalling is crucial for the induction of T-helper (Th) 17 cells [48], and there is increasing evidence that this is a key pathway in the development of chronic inflammation in the course of various skin, intestinal and lung inflammatory diseases (reviewed in [49-52]). However, to date, the particular role of Th17 cells in the pathogenesis of sarcoidosis has not been investigated [53]. The tyrosine kinase JAK2 is directly involved in signal transduction from the functional receptor complex consisting of IL-23R and IL-12 receptor $\beta 1$. The nominally significant genetic association of chronic sarcoidosis with rs10974944, which is located in the JAK2 gene (OR 1.17, 95\% CI 1.05-1.30) could, therefore, provide an additional hint to the potential importance of IL-23 signaling for the development of this phenotype, although no formal genetic SNP-SNP interaction was detected. Future experiments will clarify the role of associated SNP rs11209026 and, possibly, other causative variants in the development of chronic sarcoidosis, and how the genetic variation influences IL-23R function regarding sarcoidosis pathogenesis.

SNP rs12035082 located on chromosome 1q24.3 was significantly associated with acute sarcoidosis in the populationbased design. Replication in the independent German family sample most likely failed due to low power $(27 \%)$, while the odds ratio in the TDT analysis points to a true finding. The association signal cannot easily be attributed to a specific gene with potential functional relevance, since the SNP is located approximately $112 \mathrm{Mb}$ from the next gene. No conclusions could be drawn from in-house genome-wide association data [22], whether the signal extends further to the TNFSF18 (GITRL) or even further to the TNFSF4 (OX40L) gene (data not shown). Both have been shown to regulate $\mathrm{T}$-cell responses $[54,55]$ (reviewed in $[56,57]$ ); they could both be plausible candidates for genes with functional relevance in sarcoidosis aetiology. In order to assess an association of this region and the suggested candidate genes, validation in an independent population and fine-mapping experiments are necessary.

In general, only limited conclusions can be drawn from negative findings in this variant-centered, candidate gene approach, where we tested previously reported IBD risk variants. Disregarding the power issue, there are two major reasons why a negative finding does not exclude the specific locus as a sarcoidosis risk gene. First, for distinct diseases, "private" causative variants may exist at a common risk locus, which results in the observed overlapping pathology (e.g. granuloma formation). Secondly, it must be assumed that the majority of the markers investigated here do not represent causative SNPs, but are merely in allelic association with them. Therefore, different linkage disequilibrium structures between study populations can lead to false negative results. For example, SNP rs2066844, located in the CD risk locus NOD2, was very recently reported to be associated with a severe course of sarcoidosis [58]. Two CD risk variants (rs10521209 and rs2076756) in the NOD2 gene region were included in our study, but were not associated with either sarcoidosis or the clinical subphenotypes in this study.

In summary, this study identified the association of IL23R variant Arg381Gln with chronic sarcoidosis and provides support for this novel finding by TDT analysis in an independent family sample. We further report on an association of rs916977 (HERC2) with overall sarcoidosis and of rs12035082 (chr1q24.3 locus) with the acute subphenotype. This genetic result may point to possible aetiological similarities between sarcoidosis and other chronic inflammatory diseases, such as IBD, psoriasis and ankylosing spondylitis [7, $10,18,43]$. Our study adds further evidence to the postulated common genetic basis of inflammatory disorders. The finding may lead to new hypotheses on disease pathogenesis and encourages further functional investigation of potential causative IL23R variants and their effect on the IL23 signaling pathway in the context of sarcoidosis.

\section{STATEMENT OF INTEREST}

None declared.

\section{ACKNOWLEDGEMENTS}

The authors wish to thank all patients, families and physicians involved in the study for their cooperation. The support of the German Sarcoidosis patients association (Deutsche SarkoidoseVereinigung e.V.), the PopGen biobank and of the contributing pulmonologists is gratefully acknowledged. Finally, we want to acknowledge M. Davis, S. Ehlers, C. Fürstenau, T. Henke, I. Urbach, T. Wesse, R. Vogler and Michael Wittig at the Institute for Clinical Molecular Biology (Christian-Albrechts University, Kiel, Germany) for expert technical help.

\section{REFERENCES}

1 Brand O, Gough S, Heward J. HLA, CTLA-4 and PTPN22: the shared genetic master-key to autoimmunity? Expert Rev Mol Med 2005; 7: 1-15.

2 Seldin MF, Amos CI. Shared susceptibility variations in autoimmune diseases: a brief perspective on common issues. Genes Immun 2009; 10: 1-4. 
3 Hampe J, Cuthbert A, Croucher PJ, et al. Association between insertion mutation in NOD2 gene and Crohn's disease in German and British populations. Lancet 2001; 357: 1925-1928.

4 Hugot JP, Chamaillard M, Zouali H, et al. Association of NOD2 leucine-rich repeat variants with susceptibility to Crohn's disease. Nature 2001; 411: 599-603.

5 Kabesch M, Peters W, Carr D, et al. Association between polymorphisms in caspase recruitment domain containing protein 15 and allergy in two German populations. J Allergy Clin Immunol 2003; 111: 813-817.

6 Weidinger S, Klopp N, Rümmler L, et al. Association of CARD15 polymorphisms with atopy-related traits in a population-based cohort of Caucasian adults. Clin Exp Allergy 2005; 35: 866-872.

7 Duerr RH, Taylor KD, Brant SR, et al. A genome-wide association study identifies IL23R as an inflammatory bowel disease gene. Science 2006; 314: 1461-1463.

8 Tremelling M, Cummings FR, Fisher SA, et al. IL23R variation determines susceptibility but not disease phenotype in inflammatory bowel disease. Gastroenterology 2007; 132: 1657-1664.

9 Cargill M, Schrodi SJ, Chang M, et al. A large-scale genetic association study confirms IL12B and leads to the identification of IL23R as psoriasis-risk genes. Am J Hum Genet 2007; 80: 273-290.

10 Wellcome Trust Case Control Consortium, Australo-AngloAmerican Spondylitis Consortium (TASC), Burton PR, et al. Association scan of 14,500 nonsynonymous SNPs in four diseases identifies autoimmunity variants. Nat Genet 2007; 39: 1329-1337.

11 Karaderi T, Harvey D, Farrar C, et al. Association between the interleukin 23 receptor and ankylosing spondylitis is confirmed by a new UK case-control study and meta-analysis of published series. Rheumatology (Oxford) 2009; 48: 386-389.

12 Reveille JD, Sims AM, Danoy P, et al. Genome-wide association study of ankylosing spondylitis identifies non-MHC susceptibility loci. Nat Genet 2010; 42: 123-127.

13 Franke A, Balschun T, Karlsen TH, et al. Sequence variants in IL10, $A R P C 2$ and multiple other loci contribute to ulcerative colitis susceptibility. Nat Genet 2008; 40: 1319-1323.

14 Barrett JC, Hansoul S, Nicolae DL, et al. Genome-wide association defines more than 30 distinct susceptibility loci for Crohn's disease. Nat Genet 2008; 40: 955-962.

15 Hemminki K, Li X, Sundquist K, et al. Familial association of inflammatory bowel diseases with other autoimmune and related diseases. Am J Gastroenterol 2010; 105: 139-147.

16 Zhernakova A, van Diemen CC, Wijmenga C. Detecting shared pathogenesis from the shared genetics of immune-related diseases. Nat Rev Genet 2009; 10: 43-55.

17 Hindorff LA, Sethupathy P, Junkins HA, et al. Potential etiologic and functional implications of genome-wide association loci for human diseases and traits. Proc Natl Acad Sci USA 2009; 106: 9362-9367.

18 Rosenstiel P, Sina C, Franke A, et al. Towards a molecular risk map: recent advances on the etiology of inflammatory bowel disease. Semin Immunol 2009; 21: 334-345.

19 Müller-Quernheim J, Schürmann M, Hofmann S, et al. Genetics of sarcoidosis. Clin Chest Med 2008; 29: 391-414.

20 Valentonyte R, Hampe J, Huse $\mathrm{K}$, et al. Sarcoidosis is associated with a truncating splice site mutation in BTNL2. Nat Genet 2005; 37: 357-364.

21 Rybicki BA, Walewski JL, Maliarik MJ, et al. The BTNL2 gene and sarcoidosis susceptibility in African Americans and whites. Am J Hum Genet 2005; 77: 491-499.

22 Hofmann S, Franke A, Fischer A, et al. Genome-wide association study identifies ANXA11 as a new susceptibility gene for sarcoidosis. Nat Genet 2008; 40: 1103-1106.

23 Iannuzzi MC. Genetics of sarcoidosis. Semin Respir Crit Care Med 2007; 28: 15-21.

24 Xavier RJ, Podolsky DK. Unravelling the pathogenesis of inflammatory bowel disease. Nature 2007; 448: 427-434.
25 Franke A, Fischer A, Nothnagel M, et al. Genome-wide association analysis in sarcoidosis and Crohn's disease unravels a common susceptibility locus on 10p12.2. Gastroenterology 2008; 135 : 1207-1215.

26 Krawczak M, Nikolaus S, von Eberstein H, et al. PopGen: population-based recruitment of patients and controls for the analysis of complex genotype-phenotype relationships. Community Genet 2006; 9: 55-61.

27 WTCCC. Genome-wide association study of 14,000 cases of seven common diseases and 3,000 shared controls. Nature 2007; 447: 661-678.

28 De la Vega FM, Lazaruk KD, Rhodes MD, et al. Assessment of two flexible and compatible SNP genotyping platforms: TaqMan SNP genotyping assays and the SNPlex genotyping system. Mutat Res 2005; 573: 111-135.

29 Hampe J, Franke A, Rosenstiel P, et al. A genome-wide association scan of nonsynonymous SNPs identifies a susceptibility variant for Crohn disease in ATG16L1. Nat Genet 2007; 39: 207-211.

30 Teuber M, Koch W, Manaster C, et al. Improving quality control and workflow management in high-throughput single-nucleotide polymorphism genotyping environments. J Assoc Lab Automat 2005; 10: 43-47.

31 Wigginton JE, Cutler DJ, Abecasis GR. A note on exact tests of Hardy-Weinberg equilibrium. Am J Hum Genet 2005; 76: 887-893.

32 Purcell S, Neale B, Todd-Brown K, et al. PLINK: a tool set for whole-genome association and population-based linkage analyses. Am J Hum Genet 2007; 81: 559-575.

33 Purcell S, Cherny SS, Sham PC. Genetic Power Calculator: design of linkage and association genetic mapping studies of complex traits. Bioinformatics 2003; 19: 149-150.

34 Dupont WD, Plummer WD. PS power and sample size program available for free on the Internet. Controlled Clin Trials 1997; 3: 274.

35 Consensus conference: activity of sarcoidosis. Third WASOG meeting, Los Angeles, USA, September 8-11, 1993. Eur Respir J 1994; 7: 624-627.

36 Hunninghake GW, Crystal RG. Pulmonary sarcoidosis: a disorder mediated by excess helper T-lymphocyte activity at sites of disease activity. N Engl J Med 1981; 305: 429-434.

37 Franke A, Balschun T, Karlsen TH, et al. Replication of signals from recent studies of Crohn's disease identifies previously unknown disease loci for ulcerative colitis. Nat Genet 2008; 40: 713-715.

38 Weersma RK, Stokkers PCF, Cleynen I, et al. Confirmation of multiple crohn's disease susceptibility loci in a large DutchBelgian cohort. Am J Gastroenterol 2009; 104: 630-638.

39 Parham C, Chirica M, Timans J, et al. A receptor for the heterodimeric cytokine IL-23 is composed of IL-12Rß1 and a novel cytokine receptor subunit, IL-23R. J Immunol 2002; 168: 5699-5708.

40 Steffens M, Lamina C, Illig T, et al. SNP-based analysis of genetic substructure in the German population. Hum Hered 2006; 62: 20-29.

41 Heath SC, Gut IG, Brennan P, et al. Investigation of the fine structure of European populations with applications to disease association studies. Eur J Hum Genet, 16: 1413-1429.

42 Nunez C, Dema B, Cenit MC, et al. IL23R: a susceptibility locus for celiac disease and multiple sclerosis? Genes Immun 2008; 9: 289293.

43 Nair RP, Duffin KC, Helms C, et al. Genome-wide scan reveals association of psoriasis with IL-23 and NF-kB pathways. Nat Genet 2009; 41: 199-204.

44 Begovich AB, Chang M, Caillier SJ, et al. The autoimmune diseaseassociated IL12B and IL23R polymorphisms in multiple sclerosis. Hum Immunol 2007; 68: 934-937.

45 Fisher SA, Tremelling M, Anderson CA, et al. Genetic determinants of ulcerative colitis include the ECM1 locus and five loci implicated in Crohn's disease. Nat Genet 2008; 40: 710-712. 
46 Festen EA, Stokkers PC, van Diemen CC, et al. Genetic analysis in a Dutch study sample identifies more ulcerative colitis susceptibility loci and shows their additive role in disease risk. Am J Gastroenterol 2010; 105: 395-402.

47 Kobayashi T, Okamoto S, Hisamatsu T, et al. IL23 differentially regulates the Th1/Th17 balance in ulcerative colitis and Crohn's disease. Gut 2008; 57: 1682-1689.

48 McGeachy MJ, Chen Y, Tato CM, et al. The interleukin 23 receptor is essential for the terminal differentiation of interleukin 17producing effector $\mathrm{T}$ helper cells in vivo. Nat Immunol 2009; 10: 314-324.

49 Abraham C, Cho J. Interleukin-23/Th17 pathways and inflammatory bowel disease. Inflamm Bowel Dis 2009; 15: 1090-1100.

50 Goriely S, Cavoy R, Goldman M. Interleukin-12 family members and type I interferons in Th17-mediated inflammatory disorders. Allergy 2009; 64: 702-709.

51 Di Cesare A, Di Meglio P, Nestle FO. The IL-23/Th17 Axis in the immunopathogenesis of psoriasis. J Invest Dermatol 2009; 129: 1339-1350.
52 Nembrini C, Marsland BJ, Kopf M. IL-17-producing T cells in lung immunity and inflammation. J Allergy Clin Immunol 2009; 123: 986-994.

53 Zaba LC, Smith GP, Sanchez M, et al. Dendritic cells in the pathogenesis of sarcoidosis. Am J Respir Cell Mol Biol 2010; 42: 32-39.

54 Salek-Ardakani S, Song J, Halteman BS, et al. OX40 (CD134) controls memory $\mathrm{T}$ helper 2 cells that drive lung inflammation. J Exp Med 2003; 198: 315-324.

55 Cuzzocrea S, Ronchetti S, Genovese T, et al. Genetic and pharmacological inhibition of GITR-GITRL interaction reduces chronic lung injury induced by bleomycin instillation. FASEB J 2007; 21: 117-129.

56 Nocentini G, Riccardi C. GITR: a modulator of immune response and inflammation. Adv Exp Med Biol 2009; 647: 156-173.

57 Croft $M$. The role of TNF superfamily members in T-cell function and diseases. Nat Rev Immunol 2009; 9: 271-285.

58 Sato H, Williams HR, Spagnolo P, et al. CARD15/NOD2 polymorphisms are associated with severe pulmonary sarcoidosis. Eur Respir J 2010; 35: 324-330. 